\title{
Based on the New Idea of Improving the Teaching Effect of Physical Chemistry by Reducing Students' Burden
}

\author{
Li Han ${ }^{1, *}$, Hui Wang ${ }^{2}$, and Weijuan Gong ${ }^{3}$ \\ 1,2,3 School of Chemical and Biological Engineering, Qilu Institute of Technology, Jinan Shandong 250200, China
}

\begin{abstract}
In order to improve the professional level of college students and promote their overall development, colleges and universities adopt credit system, students are required to learn several elective courses in addition to the basic professional courses and professional skills courses, so that students are constantly passive listening to lectures, is not conducive to the cultivation of students' independent learning ability and expertise play. The course of physical chemistry is characterized by many formulas and abstract concepts. It is difficult for students to learn and takes up a long time after class. Therefore, it is very necessary to adopt diversified teaching mode, expand teaching links, ensure students' learning effect in class and reduce their learning burden after class.
\end{abstract}

\section{Introduction}

In order to improve the various abilities and qualities of contemporary college students, colleges and universities offer a wide variety of basic and professional courses, which not only enrich students' knowledge and increase their skills, but also reduce their spare time and hinder their personalized development. Abstract concepts involved in the course of physical chemistry are difficult for students to understand, and there are many and complex course formulas. Besides learning in class, students also need to spend a lot of time on preview, review and practice after class, so as to skillfully apply what they have learned. Therefore, it is necessary to reform teachers' teaching mode and students' learning mode to improve students' classroom learning effect in order to reduce students' after-class learning burden and give them more time to carry out social practice activities or give full play to their strengths[1].

\section{Reform the teaching model of teachers}

The effective teaching mode of " $1+6+1+1 "$ is adopted to increase the teaching design mode of preview and review process in class, so as to reduce the burden of after-class learning for students and ensure the learning effect of students. The teaching design of the course of physical chemistry is as follows:

\subsection{The first "1"}

The first "1" includes two parts. One is to introduce the scientific frontier of knowledge related to the main contributors of knowledge points or knowledge related to the course, the other is under the guidance of teachers, the new teaching content for preliminary preview. Take up 10 min of class time.

Introduce major contributors related to knowledge points, and through their research on knowledge, arouse students' interest in science and cultivate students' consciousness of innovation.

For example, chemist, physical chemist, chemical historian Nengst[2]. His major contributions are the proposal of the third law of thermodynamics and the establishment of the Nerst equation, the proposal of which won the Nobel Prize in 1920 and laid the foundation for the later calculation of entropy. Students learn about the development of physical chemistry knowledge, research methods and overall knowledge of physical chemistry by knowing chemists or physicists.

The introduction of the course knowledge related to science, such as the knowledge of surfactant, can be based on the hydrophilic and oil-wet structure of surfactant, the way of existence in water and solubilization, introduce the current application direction of surfactant in the field of medicine[3], so as to draw out the judgment direction and importance of critical micelle concentration, as shown in Figure 1. (a)

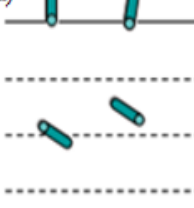

(b)
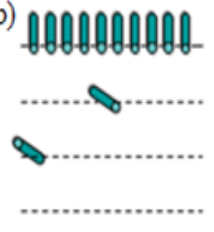

(c)

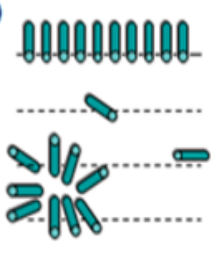

Figure 1. Distribution of surfactant in water (a) The solution concentration is extremely thin; (b) The solution reaches saturation; (c) The solution is oversaturated.

In class, the new knowledge is connected with the previous knowledge to build the knowledge framework.

\footnotetext{
* Corresponding author: 544742694@qq.com
} 
In the form of conclusion, the new contents of the course are introduced to the students first, and then explained in the later period. In this way, the students can explore and verify the knowledge instead of passively listening to the lecture, which is more conducive to stimulating the students' thirst for knowledge.

\subsection{The second "6"}

The teaching time of the teacher is $60 \mathrm{~min}$.

In order to stimulate students' interest in learning, we should pay attention to the connection between knowledge points and production and life practice in classroom teaching, and clarify the application of knowledge. For example, different volumes of pure liquid should be added to ensure the safety of the equipment when mixed solution is added to the tank of chemical plant. In the process of metal processing, how to judge the metal properties according to the heating temperature, why is the hot pot always boiling at the bottom of the pot? It can increase students' curiosity about knowledge and stimulate their learning interest and initiative.

In teaching, teachers can use PPT to combine abstract and difficult knowledge with production and life examples, and make image description in the form of pictures and videos, so as to facilitate students' understanding of knowledge. For example, when taking partial molar volume as an example to explain the concept of partial molar volume, the teaching design method is to combine the contribution of ethanol and water to the volume when they exist alone with the contribution of ethanol and water to the volume of the mixed solution when they form a mixed solution, and draw the difference between partial molar volume and molar volume, as shown in Figure 2.

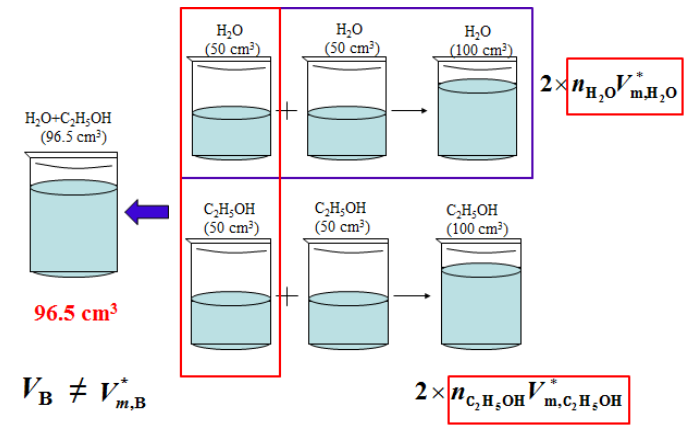

Figure 2. The difference between partial moles and moles

After the knowledge points are explained, an example combining with production application is designed so that students can flexibly apply what they have learned to solve practical problems, as shown in Figure 3.

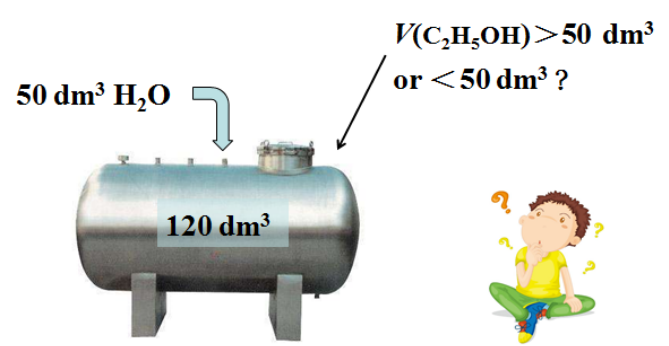

Figure 3. Partial molar quantities are used as examples

This process is the normal teaching process for teachers. In teaching, teachers can use PPT to vividly describe abstract and difficult knowledge with pictures and videos, and at the same time, cases can be used to enhance students' understanding of knowledge. Teachers in the interpretation of the relevant knowledge, want to remember learning main body is a student, they understand and can skilled application of relevant knowledge is the teachers' teaching purpose, so in the process of teaching, teacher would make up a student's practice unifies, and proper insert turning classroom[4], lets the student can speak out with the knowledge, is helpful for students to recognize their mastery of knowledge and understand thoroughly, optimizing the study effect.

Such as system classification, isolated, closed and open systems, teacher pure interpretation of knowledge, students are likely to rote learning, not the application, if it takes the form of PPT, thermos bottle to different category system and the actual life whether the heat preservation and open situation, and with graphic signal, the concept of different category system, deepen the impression of knowledge at the same time, students can more fully understand knowledge, and skilled application, as shown in Figure 4. Then add a thinking question, such as what system the human body belongs to, let the students think, exercise the students' knowledge application ability and problem analysis ability, stimulate students' interest in the course.
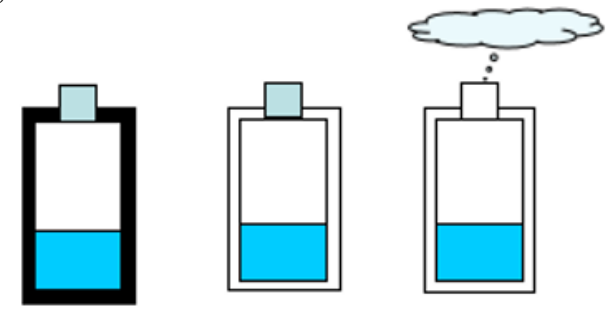

Figure 4. Classification of different systems

For example, for the derivation of important formulas, teachers should adopt the way of thinking guidance combined with students' practice, so that students can learn, think and practice at the same time. When practicing, we can use the form of group discussion to let more students participate in the study. After the practice, a student will be selected on a voluntary basis to explain the derivation process of the formula. Students' enthusiasm for learning will be stimulated through their self-presentation to ensure the learning effect, which will not only exercise their language expression ability, but also cultivate their independent thinking ability.

Such as: $1 \mathrm{~mol}, 263.15 \mathrm{~K}$ of supercooled water in constant solidification under $101.325 \mathrm{kPa}$ is $263.15 \mathrm{~K}$ 
under ice system entropy change $\Delta \mathrm{S}$ of religion. The teacher first put forward a question, whether the condensation of $\mathrm{H} 2 \mathrm{O}(\mathrm{l})$ into ice at $263.15 \mathrm{~K}$ and 101.325 $\mathrm{kPa}$ is a reversible phase change, and whether the entropy change in the process can be found in the appendix, so that students can think about the method of calculating the entropy change of irreversible phase change. Then, in the form of retrospection, the teacher proposed the characteristics of the state function and guided the students to design an imaginary path for the irreversible phase transition process, so as to calculate the entropy change step by step and get the total entropy of the system, as shown in Figure 5. Then review the last lesson knowledge entropy criterion, the condition of judgment system of total entropy can be spontaneous or not for cold water freezing process criterion, then the method of environmental entropy change in isolation system is derived. Finally, the direction and limit of the process are judged by the entropy change of the isolated system.

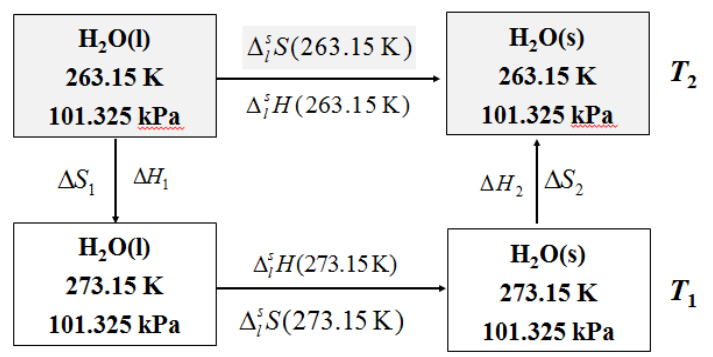

Figure 5. Hypothetical approach for calculating entropy change during irreversible phase transition

In the whole process of teaching knowledge points, the logicality of knowledge is the leading factor and the links are linked together to form a chain of knowledge in students' consciousness, which is conducive to students' understanding of the whole knowledge.

\subsection{The third "1"}

The exercise is consolidated with an occupancy time of $10 \mathrm{~min}$

Through typical examples of the knowledge learned in the course, the state of students' listening is changed to active thinking, so that students' attention can be focused again. Through the process of writing by hand, to verify the learning effect of students in class, check and fill in the blanks, so that students have a deeper understanding of the knowledge, but also exercise the students' memory ability, learning ability and knowledge application ability.

\subsection{The fourth "1"}

Establish a knowledge system based on the new knowledge learned this time and the knowledge learned last time, and the class time is $10 \mathrm{~min}$.

Students form a knowledge system by associating the newly learned knowledge with the already learned knowledge, so it is not easy to make mistakes in the application of formulas when solving problems.

\section{Reform students' learning mode}

\subsection{Make full use of the Internet for learning}

In the current rapid development of internet, students' learning style has become diversified, in addition to listen carefully in class, teachers can also be done through the network teaching platform release task, exercises and referral. In addition, online teaching platforms such as MOOC, as shown in Figure 6, Wisdom Tree, as shown in figure 7, and Fan-ya, as shown in Figure 8, can be used to independently learn excellent courses of Physical Chemistry from different universities and famous teachers, so as to supplement, consolidate and expand the knowledge learned.

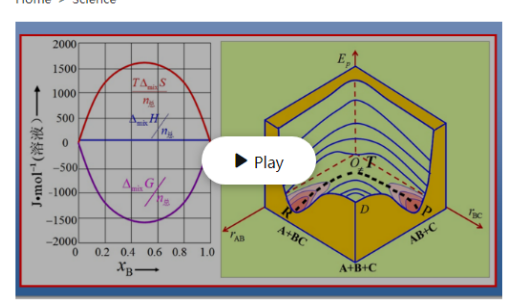

Physical Chemistry (Part 2) Class 6 Start time: September 07, 2020 January 9, 2021 Class hours: 3 hours per week

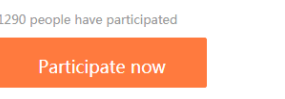

Figure 6. Interface of excellent courses in physical chemistry, MOOC teaching platform

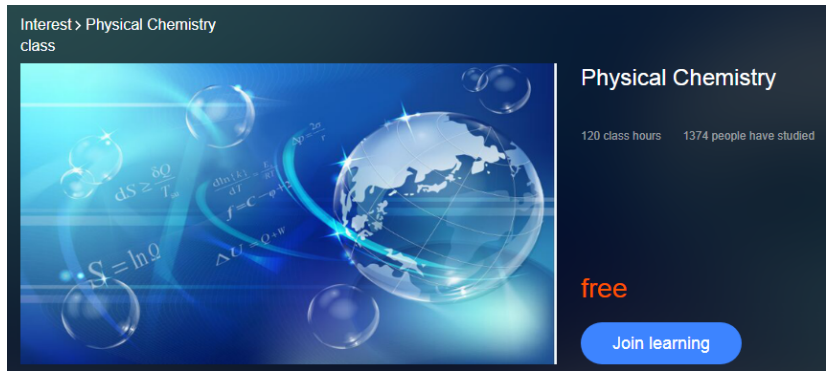

Figure 7. Interface of physical chemistry, a smart tree teaching platform

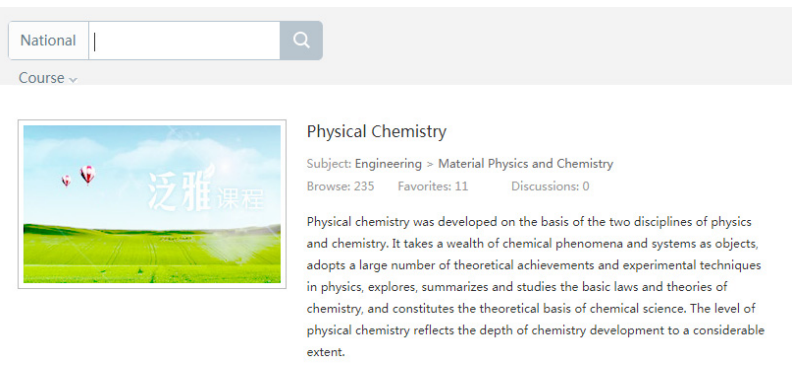

Figure 8. The course interface of physical chemistry of Fan-ya platform

If you encounter unclear knowledge points in the review process, you can repeatedly check the courseware content uploaded by the teacher on the network teaching platform, as shown in Figure 9. 


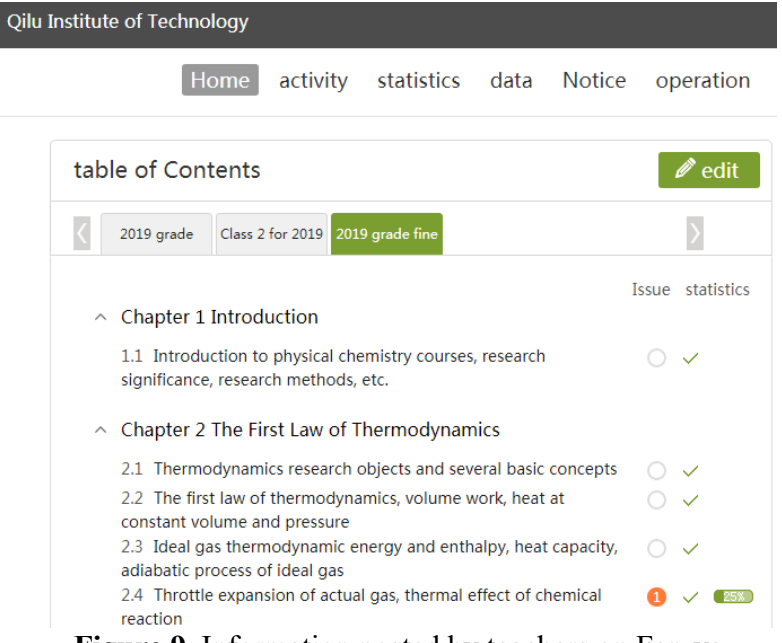

Figure 9. Information posted by teachers on Fan-ya

\subsection{Set up student learning teams}

For students with strong learning initiative and enthusiasm, learning through multiple channels can not only deepen the understanding of theoretical knowledge of the course, but also timely understand the frontiers of the subject, and improve the awareness and thinking of scientific research. But for learning foundation is weak and low learning initiative of students, need with the aid of outside force to urge, to improve their learning effect, so the teacher in the student team, should pay attention to learning seriously, hard work and study purpose is not clear, study habits lazy student to carry on the reasonable team, let its mutual learning, mutual supervision, mutual encouragement, increase students' team consciousness and sense of responsibility.

\subsection{Flipped classroom}

Relatively simple course related knowledge, the teacher uses the flip class, students can through ten thousand parties, hownet database or different versions of the physical chemistry textbooks, independent data access editors need to report in class knowledge unit, to exchange views with each other, in the form of team improve the report content, every student involved, experience knowledge need to expand and pay attention to the content of the problem. Finally, draw lots to choose a student in the group to report. Let him/her explain knowledge to other students in the role of a teacher. In this way, no matter in class or after class, students' sense of urgency in learning can be improved, as well as their ability to look up information and enhance their confidence in learning.

\section{Carry out confirmatory experiments and design experiments irregularly according to the knowledge content}

Students should not only understand the application of theoretical knowledge in practice, but also understand the corresponding prerequisites, principles, matters needing attention and solutions to problems. By carrying out design experiments, students can understand what, why and how the relevant theoretical knowledge of physical chemistry courses is, so as to truly put what they have learned into practice. Be able to make a breakthrough in study, practice, study and practice, and solve practical problems in complex life and production. Through the design experiment, students' observation ability, thinking ability and practical ability can be strengthened, and their innovation consciousness can be further developed. Such as the design experiment $\mathrm{BaSO} 4$ solubility product determination, before class, students design the experimental purpose, experimental principle, experimental instruments and reagents, experimental steps, data processing and matters needing attention by looking up data. Through the design, the students' independent thinking ability, knowledge application ability and innovation ability have been trained.

\section{References}

1. Li S S, Zhang X H. (2018) The teaching reform of physical chemistry from the perspective of curriculum interest. Journal of Lan Zhou Univerdity of Arts and Science (Natural Sciences), 32: 118-124.

2. https://baike.baidu.com/item/Nengst/7204721?fr $=\mathrm{al}$ addin.

3. Jia Q F, Ni X M, Wu H M, Li Z H. (2018) Physicochemical parameters and thermodynamic behavior of sodium dodecyl sulfate at different $\mathrm{NaCl}$ concentrations. Chemical Industry and Engineering Progress, 37: 181-186.

4. Zhang L, Li P, Chai j w. (2020) Research on improving flipped classroom teaching with projectbased teaching under the background of new engineering. Journal of University of Electronic Science and Technology of China (Social Sciences Edition), 22: 1-6.

5. Guo C, Fang H, Xia X, Wang z X. (2020) Characteristics and reflection of the construction of physical chemistry (1) MOOC. Journal of Anqing Normal University (Natural Science Edition), 26: 102-106. 